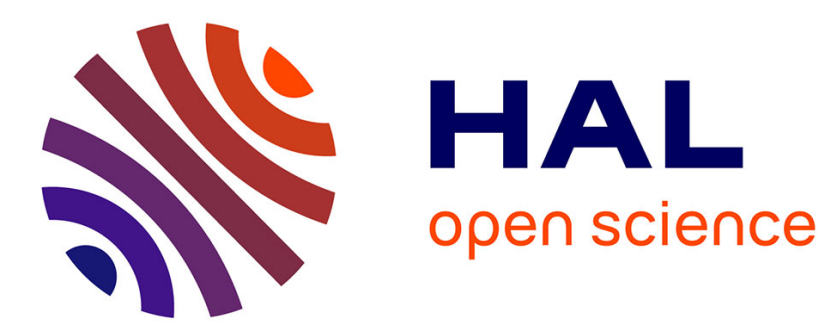

\title{
Thermodynamic and Kinetic Origins of the Vitreous Transition
}

\author{
Robert F Tournier
}

\section{To cite this version:}

Robert F Tournier. Thermodynamic and Kinetic Origins of the Vitreous Transition. Intermetallics, 2012, 30, 10.1016/j.intermet.2012.03.024 . hal-02937054

\section{HAL Id: hal-02937054 https://hal.science/hal-02937054}

Submitted on 12 Sep 2020

HAL is a multi-disciplinary open access archive for the deposit and dissemination of scientific research documents, whether they are published or not. The documents may come from teaching and research institutions in France or abroad, or from public or private research centers.
L'archive ouverte pluridisciplinaire HAL, est destinée au dépôt et à la diffusion de documents scientifiques de niveau recherche, publiés ou non, émanant des établissements d'enseignement et de recherche français ou étrangers, des laboratoires publics ou privés. 


\title{
Thermodynamic and Kinetic Origins of the Vitreous Transition
}

\author{
Robert F. Tournier \\ Centre National de la Recherche Scientifique, Université Joseph Fourier, Consortium de Recherches \\ pour l'Emergence de Technologies Avancées, B.P. 166, 38042 Grenoble Cedex 09, France \\ E-mail: Robert.Tournier@grenoble.cnrs.fr, Tel : +33608716878, Fax: +33476881280
}

Keywords: 64.70.kj Glasses, 64.70.P Glass Transitions, 64.70pe Metallic Glasses, 64.70ph. Non Metallic Glasses, 64.70 pj Polymers, 64.60 Q- Nucleation

\begin{abstract}
:
A unique vitreous transition temperature $\mathrm{T}_{\mathrm{g}}^{*}$ has been recently determined by an extrapolation of the fully-relaxed enthalpy $\mathrm{H}_{\mathrm{r}}$ down to zero as a function of temperature. This exothermic heat is linearly decreasing with temperature and the slope $\mathrm{dH}_{\mathrm{r}} / \mathrm{dT}$ is equal to the specific heat jump from the vitreous to the undercooled state and to the specific heat difference between crystal and melt because a freezing of atom freedom degrees in the liquid state is associated with the vitreous transition at $\mathrm{T}^{*} \mathrm{~g}$. It has been also shown that $\mathrm{T}^{*} \mathrm{~g}$ is a material constant which is equal to a crystal homogeneous nucleation temperature in glassforming melts. A volume energy saving $\varepsilon_{\mathrm{v}}$ has been added to the classical Gibbs free energy change $\theta \times \Delta \mathrm{H}_{\mathrm{m}} / \mathrm{V}_{\mathrm{m}}$ for a crystal formation in a melt where $\Delta \mathrm{H}_{\mathrm{m}}$ is the fusion heat, $\mathrm{V}_{\mathrm{m}}$ the molar volume, $\theta=\left(\mathrm{T}-\mathrm{T}_{\mathrm{m}}\right) / \mathrm{T}_{\mathrm{m}}$ and $\mathrm{T}_{\mathrm{m}}$ the melting temperature. We show here that $\varepsilon_{\mathrm{v}}$ is equal to the Laplace pressure change ( $\left.\mathrm{p}-\mathrm{p}_{0}\right)$ as compared to the classical pressure $\mathrm{p}_{0}=\theta \times \Delta \mathrm{H}_{\mathrm{m}} / \mathrm{V}_{\mathrm{m}}$ acting on crystals imbedded in a melt. The model is able to strictly predict the precise values of the Vogel-Fulcher-Tamman temperature, the energy saving $\varepsilon_{\mathrm{v}}$, the Laplace pressure $\mathrm{p}$ and the ratio $\mathrm{T}_{\mathrm{g}} / \mathrm{T}_{0 \mathrm{~g}}$ of fragile liquids when the equilibrium transition temperature $\mathrm{T}_{\mathrm{g}}$ is known.
\end{abstract}


These predictions do not work in strong liquids because there are many possible values of $\mathrm{T}_{\mathrm{g}}$ when the VFT temperature is known. The viscosity at $\mathrm{T}^{*} \mathrm{~g}$ has to be known to predict this temperature. The fragility indexes of fragile glasses and the map of fragility indexes of strong liquids depending on the $\mathrm{T}^{*}$ and $\mathrm{T}_{0 \mathrm{~g}}$ have been also calculated as a function of $\mathrm{T}_{\mathrm{g}}^{*}$.

\section{1- Introduction}

The debate about the origin of the vitreous state seems to be closed among materials scientists because the freezing of liquid-state below a temperature $\mathrm{T}_{\mathrm{g}}$ called the vitreous or glass transition is attributed up to now to a kinetic origin instead of a thermodynamic one in

spite of the existence of some specific heat measurements using a stepwise differential scanning calorimetry (DSC) technique which shows that the transition temperature is fixed and only depends on the chemical composition. A reversible specific heat shows a jump at a temperature $\mathrm{T}_{\mathrm{g}}^{*}$ regardless the heating and cooling rates and an exothermic or endothermic heat is relaxed during the relaxation time at temperatures $\mathrm{T}_{\mathrm{g}}$ smaller or larger than $\mathrm{T}_{\mathrm{g}}{ }_{\mathrm{g}}$ when $\mathrm{AS}_{2} \mathrm{Se}_{3}$ and $\mathrm{As}_{2} \mathrm{~S}_{3}$ samples are annealed at $\mathrm{T}_{\mathrm{g}}$ after quenching at lower temperatures [1-3].

We assume that a thermodynamic transition temperature $\mathrm{T}_{\mathrm{g}}$ exists among the time dependent transition temperatures $\mathrm{T}_{\mathrm{g}}$ in glass formers which does not depend on the heating and cooling rates and we look at some consequences of this assumption. A relaxation time $\tau$ exists at any temperature around $\mathrm{T}_{\mathrm{g}}^{*}$; $\tau$ increases when the temperature decreases and is viewed as a time-lag in crystal transient nucleation necessary to induce the transformation of an undercooled fragile liquid in a frozen vitreous state [4]. The sample can be quenched in the undercooled state down to temperatures $\mathrm{T}_{\mathrm{g}}$ lower than $\mathrm{T}_{\mathrm{g}}$ as shown in Figure 1. A transformation in an equilibrium state occurs at any temperature smaller or larger than $\mathrm{T}_{\mathrm{g}}$ 
and is accompanied by a relaxed enthalpy which does not depend on time when it is saturated. The relaxation time has to be much longer than the time necessary to homogenize the temperature inside the sample before starting the enthalpy measurement. The fully-relaxed enthalpy $\mathrm{H}_{\mathrm{r}}$ at $\mathrm{T}_{\mathrm{g}}$ is equal to the surface $\mathrm{ABCD}$ in Figure 1 when the sample has been cooled down to this temperature. The enthalpy $\mathrm{H}_{\mathrm{r}}$ is an endothermic heat equal to the surface CDEF when the sample is heated from the vitreous state to a temperature $T_{g}$ larger than $T^{*}$. The following equation applied to fragile glass-forming melts is obeyed:

$$
H_{r}=\int_{T_{g}}^{T_{g}^{*}} \Delta C_{p_{g l}} \mathrm{dT}
$$

where $\Delta \mathrm{C}_{\mathrm{pgl}}$ is equal to the specific heat difference $\mathrm{C}_{\mathrm{pl}}-\mathrm{C}_{\mathrm{pg}}$ between the undercooled and vitreous or crystallized states in agreement with a whole freezing of the melt [4]. This description is based on the assumption that the relaxation time is, in fact, a time-lag related to transient homogeneous nucleation. It is corroborated by the viscosity increase with time towards the equilibrium of the vitreous state at temperatures smaller than $\mathrm{T}_{\mathrm{g}}$ because we expect that the viscosity in the vitreous state has to be larger than the one in the undercooled quenched melt [5-7].

An endothermic heat bump depending on the heating rate characterizes the transition glass-melt at $\mathrm{T}_{\mathrm{g}}$ when the vitreous transition is determined with a technique of differential scanning calorimetry (DSC) without any anomaly at $\mathrm{T}^{*}$. It can be deduced that the exothermic heat ought to be a linear function of the temperature and then $\Delta \mathrm{C}_{\mathrm{pgl}}$ cannot depend on temperature. The vitreous transition $\mathrm{T}^{*} \mathrm{~g}$ would be defined, in this description, at the disappearance temperature without any anomaly at $\mathrm{T}^{*} \mathrm{~g}$. The disappearance temperature $\mathrm{T}_{\mathrm{g}}$ of the relaxed enthalpy is obtained, in these conditions, using a linear extrapolation of $\mathrm{H}_{\mathrm{r}}$ down to zero. The $\mathrm{T}^{*}{ }_{\mathrm{g}}$ would separate the frozen and undercooled states. 
The fully-relaxed enthalpies of $\mathrm{Ti}_{40} \mathrm{Zr}_{25} \mathrm{Ni}_{8} \mathrm{Cu}_{9} \mathrm{Be}_{18}$, glycerol, $\mathrm{Zr}_{58.5} \mathrm{Cu}_{15.6} \mathrm{Ni}_{12.8} \mathrm{Al}_{10.3} \mathrm{Nb}_{2.8}$ and $\mathrm{As}_{2} \mathrm{Se}_{3}$ are linear functions of $\mathrm{T}$ [4]; the thermodynamic transition temperature $\mathrm{T}_{\mathrm{g}}$ exists and has been extrapolated from the measurements of the fully-relaxed enthalpy. A reversible specific heat jump is observed in $\mathrm{As}_{2} \mathrm{Se}_{3}$ at the same temperature $\mathrm{T}^{*} \mathrm{~g}$ with a stepwise DSC technique regardless the cooling and heating rates [1-3]. The specific heat jump of $\mathrm{As}_{2} \mathrm{Se}_{3}$ calculated from (1) is equal to the measured one in perfect agreement with the description given in Figure 1. $\Delta \mathrm{C}_{\mathrm{lg}}$ is a little smaller in the other glassforming melts than that measured by DSC because of the existence of a residual endothermic contribution.

The idea of a thermodynamic transition $\mathrm{T}^{*}{ }_{\mathrm{g}}$ is so much rejected that the disappearance temperature of the relaxed enthalpy is never used to determine the glass transition in spite of the fact that this quantity does not depend on time when it is saturated. The equilibrium viscosity values $\eta(T)$ below $T_{g}$ are also considered, up to now, as belonging to the undercooled state because the vitreous state is viewed as a continuous prolongation of the liquid state at lower temperatures. A continuous Vogel-Fulcher-Tammann law given by (2) including values below and above $\mathrm{T}_{\mathrm{g}}$ is used to determine the VFT temperature $\mathrm{T}_{0}$ and the fragility index $\mathrm{D}^{*}[5-7]$ :

$$
\eta=\eta_{0} \exp \left(\frac{D^{*} T_{0}}{T-T_{0}}\right)
$$

This analysis tends to deny the observation of a phase transition using the viscosity measurement. Nevertheless, an increase of viscosity exists during the relaxation time which is the time lag for the formation of a cluster distribution. The viscosity values of the quenched state belong to the undercooled state and the equilibrium viscosity to the frozen vitreous state. The reversible specific heat measurement however indicates that the transition always occurs 
at the same temperature $\mathrm{T}^{*} \mathrm{~g}$ while the exothermic heat depends on the temperature of annealing. This transformation of the undercooled melt in a frozen state at any temperature $\mathrm{T}_{\mathrm{g}}$ would only produce an exothermic heat while the equilibrium reversible transition of fragile liquids would always occur at $\mathrm{T}_{\mathrm{g}}$ because there is a minimum of the energy saving at this temperature [1-3].

The relaxation times are too long to be related to a first or second order phase transition. They have to be associated with a crystal nucleation temperature leading in a first step to a vitreous phase on the long way to a crystallized phase. The transient homogeneous nucleation time to form a cluster distribution and the steady-state nucleation time all together lead to unattainable time lags before the occurrence of a homogeneous crystallization [8]. The Gibbs free energy change $\theta \times \Delta \mathrm{H}_{\mathrm{m}} / \mathrm{V}_{\mathrm{m}}$ associated with a cluster formation in a melt has to be increased to reflect the volume energy saving $\varepsilon_{\mathrm{v}}$ associated with Fermi energy equalization of nascent crystals and melts. The reduced temperature $\theta$ is equal to $\left(T-T_{m}\right) / T_{m}, T_{m}$ the melting temperature, $\Delta \mathrm{H}_{\mathrm{m}}$ the fusion heat per mole and $\mathrm{V}_{\mathrm{m}}$ the molar volume [9-13]. A similar proposal has been made for crystal formation in metallic and nonmetallic melts because the chemical potential of a small cluster ought to differ from the bulk value in presence of a density difference between cluster and melt and of a Laplace pressure $\mathrm{p}$ added to the classical pressure $\mathrm{p}_{0}$ of the melt [14]. The energy saving as compared to $\theta \times \Delta \mathrm{H}_{\mathrm{m}}$ would be equal to (p$\left.\mathrm{p}_{0}\right) \times \mathrm{V}_{\mathrm{m}}$. We have recently shown that these two quantities are equal for titanium at the melting temperature [15].

The energy saving coefficient $\varepsilon_{\mathrm{ls}}=\varepsilon_{\mathrm{v}} / \Delta \mathrm{H}_{\mathrm{m}} \times \mathrm{V}_{\mathrm{m}}$ is a function of $\theta^{2} ; \varepsilon_{\mathrm{ls}}$ is equal to a maximum value $\varepsilon_{\mathrm{ls} 0}$ at $\mathrm{T}_{\mathrm{m}}$ corresponding to the maximum of the Fermi energy difference and to zero at $\theta=\theta_{0 \mathrm{~g}}$ where $\theta_{0 \mathrm{~g}}$ is equal to the Vogel-Fulcher-Tammann temperature which corresponds to the free-volume disappearance temperature $[9,10]$. Metallic clusters formed in 
a liquid element with a radius smaller than the critical one has a one-particle-density of states of s state electrons disappearing at low radius. The energy saving associated with cluster radii smaller than 0,5 nanometer is a quantified quantity which leads to a conduction gap opening. The same size-dependent changes in the electronic structure of metal clusters in vacuum have been observed by scanning tunneling spectroscopy. Metallic clusters in melts have the same properties than in vacuum [15]. The new crystal nucleation temperature $\theta_{21 \mathrm{~s}}$ is equal to $\left(\varepsilon_{\mathrm{ls}^{-}}\right.$ $2) / 3$ instead of $-2 / 3$ as predicted by the classical nucleation model with $\varepsilon_{\text {ls }}=0$. These two relations have to be respected at the homogeneous nucleation temperature and lead to a quadratic equation that has been used to determine $\theta_{2 \mathrm{ls}}$ as a function of $\varepsilon_{\mathrm{ls} 0}$ and $\theta_{0 \mathrm{~g}}[9,11]$. The Angell's description in terms of strong and fragile glass-forming melts is found when we assume that the vitreous transition occurs at the homogeneous nucleation temperature of glass-forming melts. The quadratic equation solutions have been used to determine, in agreement with many experimental results, the relations between the VFT temperatures $T_{0 \mathrm{~g}}$ governing the temperature dependence of relaxation time of many melts, the vitreous transition $\mathrm{T}_{\mathrm{g}}^{*}$ and the energy saving coefficient $\varepsilon_{\mathrm{ls} 0}$ at $\mathrm{T}_{\mathrm{m}}$.

The quantified energy savings of crystals having a radius equal or smaller than the critical one depends on the number of s state electrons which are transferred from a nascent crystal to the melt. A spherical attractive potential energy is created which is screened in the melt by conduction electrons; $\varepsilon_{\mathrm{ls} 0}$ at $\mathrm{T}=\mathrm{T}_{\mathrm{m}}$ is quantified, depends on the crystal radius $\mathrm{R}_{\mathrm{nm}}$ and corresponds to the first energy level of one-s electron moving in vacuum in the same spherical attractive potential despite the fact that the charge screening is built by many-body effects $[9,11,15]$. The existence of an energy saving $\varepsilon_{\mathrm{v}}$ has for consequence that some crystals having a radius smaller than the critical one survive above $T_{m}$, act as growth nuclei in undercooled melts and produce crystallization at temperatures much higher than the 
homogeneous nucleation temperature when the cooling rate is too weak. These quantified values of $\varepsilon_{\mathrm{ls} 0}$ have been used to predict the undercooling temperatures of gold and titanium in perfect agreement with experiments $[15,16]$.

This model is used here to describe the energy saving variation when the glass transition temperature $\mathrm{T}_{\mathrm{g}}$ is varied near the thermodynamic transition $\mathrm{T}_{\mathrm{g}}$ of several glassforming melts. Several maps are established which represent $\mathrm{T}_{\mathrm{g}}^{*} / \mathrm{T}_{0 \mathrm{~g}}$ versus the reduced glass transition temperature $\theta_{\mathrm{g}}$, the energy saving coefficients $\varepsilon_{1 \mathrm{~s} 0}$ of strong and fragile glasses versus $\theta_{\mathrm{g}}$. The energy saving coefficient $\varepsilon_{\mathrm{ls} 0}$ is always larger in fragile glass-forming melts than that of strong melts.

We also show, for the first time, that the quantity $\left(\mathrm{p}-\mathrm{p}_{0}\right) \times \mathrm{V}_{\mathrm{m}} / \Delta \mathrm{H}_{\mathrm{m}}$ is equal to the energy saving coefficient $\varepsilon_{\mathrm{ls} 0}$ per mole at the melting temperature and to $\varepsilon_{\mathrm{ls}}$ down to $\mathrm{T}_{\mathrm{g}}$ regardless of melts. It explains why this model can be used in nonmetallic glass-forming melts [4].

\section{2- The Gibbs free energy change associated with crystal formation in melts is completed by an energy saving}

Transformations liquid-solid always induce changes of the conduction electron number per volume unit, and sometimes per atom. The equalization of Fermi energies of a spherical particle containing $\mathrm{n}$ atoms having a radius $\mathrm{R}$ smaller than a critical value $\mathrm{R}{ }^{*}{ }_{21 \mathrm{~s}}(\theta)$ and of its melt produces an unknown energy saving $\varepsilon_{\mathrm{v}}$ per volume unit. The $\varepsilon_{\mathrm{v}}$ value is equal to a fraction $\varepsilon_{\text {ls }}$ of the molar fusion heat $\Delta \mathrm{H}_{\mathrm{m}}$ per molar volume $\mathrm{V}_{\mathrm{m}}$. This energy has been included in (3) which is the Gibbs free energy change $\Delta \mathrm{G}_{2 \mathrm{ls}}(\theta)$ associated with a crystal 
formation in metallic melts, $\theta$ being equal to $\theta=\left(T-T_{m}\right) / T_{m}$ and $T_{m}$ the melting temperature [9-13];

$$
\Delta G_{2 l s}(R, \theta)=\frac{\Delta H_{m}}{V_{m}}\left(\theta-\varepsilon_{l s}\right) 4 \pi \frac{R^{3}}{3}+4 \pi R^{2} \frac{\Delta H_{m}}{V_{m}}\left(\frac{V_{m}}{N_{A}}\right)^{1 / 3} \alpha_{2 l s}
$$

where

$$
\begin{gathered}
\alpha_{2 l s}=\left(1+\varepsilon_{l s}\right)\left[\frac{N_{A} k_{B} \ln \left(K_{l s}\right)}{36 \pi \Delta S_{m}}\right]^{1 / 3}, \\
\ln \left(J . \mathrm{v} . t_{s n}\right)=\ln \left(K_{l s} \cdot \mathrm{v} \cdot t_{s n}\right)-\left[\frac{\Delta G_{2 l s}^{*}-\Delta G_{n m}}{k_{B} T}\right] \\
\ln \left(K_{\lg s}\right)=\ln \left(\frac{A \eta_{0}}{\eta}\right)=(\ln A) \pm 2-\frac{B}{\left(T-T_{0 g}\right)}, \\
\frac{\Delta G_{2 l s}^{*}}{K_{B} T}=\frac{12}{81} \frac{\left(1+\varepsilon_{l s}\right)^{3}}{\left(\theta-\varepsilon_{l s}\right)^{2}} \frac{\ln K_{l s}}{(1+\theta)} \\
R_{2 l s}^{*}(\theta)=-\alpha_{2 l s} \frac{2}{\theta-\varepsilon_{l s}}\left(\frac{V_{m}}{N_{A}}\right)^{1 / 3}
\end{gathered}
$$

$\mathrm{N}_{\mathrm{A}}$ is Avogadro's number, $\mathrm{k}_{\mathrm{B}}$ Boltzmann's constant, $\Delta \mathrm{S}_{\mathrm{m}}$ in (4) the fusion entropy, $\mathrm{J}$ in (5) the nucleation rate, $\Delta \mathrm{G}^{*}{ }_{21 \mathrm{~s}}$ the critical energy barrier of crystal growth given by $(7), \mathrm{R}^{*}{ }_{21 \mathrm{~s}}$ the growth critical radius given by (8), $v$ the sample volume, $t_{\mathrm{sn}}$ in (5) the steady-state nucleation time, $\mathrm{T}_{0 \mathrm{~g}}$ in (5) the disappearance temperature of the free-volume in glass-forming melts having a viscosity following a Vogel-Fulcher-Tammann law [17]; $\ln \mathrm{A}$ in (6) is equal to 90 in liquid elements and to about 100 at the vitreous transition $T_{g}$ when $K_{1 s}$ in (5) and (6) is defined in $\mathrm{m}^{-3} \cdot \mathrm{s}^{-1}[4,9,18] ; \mathrm{B} /\left(\mathrm{T}_{\mathrm{g}}-\mathrm{T}_{0 \mathrm{~g}}\right)$ in (6) is equal to 36 (see $\left.7-\right)$. The contribution of unmelted crystals (clusters) of radius $\mathrm{R}_{\mathrm{nm}}$ to the reduction of the critical energy barrier is given by (3) 
with $R=R_{n m}$ being constant and equal to $R_{n m}$ when $T$ decreases down to a temperature for which $\Delta \mathrm{G}_{\mathrm{eff}} / \mathrm{k}_{\mathrm{B}} \mathrm{T}=\Delta \mathrm{G}^{*}{ }_{21 \mathrm{~s}} / \mathrm{k}_{\mathrm{B}} \mathrm{T}-\Delta \mathrm{G}_{\mathrm{nm}} / \mathrm{k}_{\mathrm{B}} \mathrm{T}$ in (5) becomes equal to $\ln \mathrm{K}_{\mathrm{ls}}[8,19]$. The classical equations $\Delta \mathrm{G}_{1 \mathrm{ls}}(\theta)$ and $\alpha_{1 \mathrm{ls}}$ are obtained with $\varepsilon_{\mathrm{ls}}=0[18,19]$. The experimental values of $\alpha_{1 \mathrm{ls}}$ and of the lowest undercooling temperatures have been used to determine $\alpha_{21 \mathrm{~s}}$ and $\varepsilon_{1 \mathrm{~s}}[10,18]$. The thermal variation of $\varepsilon_{\mathrm{ls}}$ is an even function of $\theta$ given by (9) where $\theta_{0 \mathrm{~g}}=\left(\mathrm{T}_{0 \mathrm{~g}}-\mathrm{T}_{\mathrm{m}}\right) / \mathrm{T}_{\mathrm{m}}$ $[9,10]$; then, the fusion heat of unmelted crystals remains equal to $\Delta \mathrm{H}_{\mathrm{m}}$ regardless of their radius.

$$
\varepsilon_{\mathrm{v}}=\varepsilon_{l s} \frac{\Delta H_{m}}{V_{m}}=\varepsilon_{l s 0}\left(1-\frac{\theta^{2}}{\theta_{0 g}^{2}}\right) \frac{\Delta H_{m}}{V_{m}}
$$

The derivative $\mathrm{dJ} / \mathrm{d} \theta$ is proportional to $\left(3 \theta-\varepsilon_{\mathrm{ls}}+2\right)$ when $\Delta \mathrm{G}_{\mathrm{nm}}=0[10]$; the homogeneous nucleation temperature $\mathrm{T}_{21 \mathrm{~s}}$ is given by (10) when $\left(3 \theta-\varepsilon_{1 \mathrm{~s}}+2\right)=0$; at $\mathrm{T}=\mathrm{T}_{21 \mathrm{~s}}$, we have in (5) $\mathrm{J}=1 \mathrm{~m}^{-3} \mathrm{~s}^{-1}, \mathrm{v} \cdot \mathrm{t}_{\mathrm{sn}}=1, \ln \left(\mathrm{J} \cdot \mathrm{v} \cdot \mathrm{t}_{\mathrm{sn}}\right)=0$ and $\ln \mathrm{K}_{\mathrm{ls}}=\Delta \mathrm{G}^{*}{ }_{2 \mathrm{~s}} / \mathrm{k}_{\mathrm{B}} \mathrm{T}_{2 \mathrm{ls}}:$

$$
\theta_{2 l p s}=\frac{\left(T_{2 l s}-T_{m}\right)}{T_{m}}=\frac{\varepsilon_{l s}-2}{3}
$$

We apply these equations to glass-forming melts assuming that the glass transitions occurs at $\mathrm{T}_{\mathrm{g}}^{*}=\mathrm{T}_{21 \mathrm{~s}}\left(\right.$ or $\left.\theta_{\mathrm{g}}=\theta_{21 \mathrm{~s}}\right)[4]$.

\section{3- The crystal homogeneous nucleation temperature and the vitreous transition}

The crystal growth critical energy $\Delta \mathrm{G}^{*}{ }_{21 \mathrm{~s}}$ given by (1) divided by $\ln \mathrm{K}_{\mathrm{ls}}$ is plotted in 
Figure 2 as a function of the reduced temperature $\theta$ using several values of $\varepsilon_{\mathrm{ls} 0}$ covering the entire window of bulk glass- forming melts. The homogeneous nucleation temperature $\theta_{21 \mathrm{~s}}$ occurs at temperatures increasing with $\varepsilon_{\mathrm{ls} 0}$. The equality $\Delta \mathrm{G}^{*}{ }_{2 \mathrm{ls}} \cong \ln \mathrm{K}_{\mathrm{ls}}$ is respected in a broad window of temperatures above the nucleation temperatures; $\theta_{21 \mathrm{~s}}$ strictly depends on the energy saving which increases with $\varepsilon_{\mathrm{ls} 0}$ and $\theta_{0 \mathrm{~g}}$ as shown by (9) while $\ln K_{\mathrm{ls}}$ depends on the temperature in (6) through the viscosity [8]. The crystal homogeneous nucleation temperature is also determined by kinetic effects through $\ln K_{1 s}$. The relaxation time is viewed as the transient nucleation time $\tau^{\text {ns }}$ given by (11):

$$
\tau^{n s}=\frac{\pi N}{12 \Gamma \times K_{l s}}=\frac{\pi N}{12} J_{c}\left(\frac{3 \pi}{\ln K_{l s}}\right)^{1 / 2} \exp (-\ln A) \times \exp \left(\frac{B}{T-T_{0 g}}\right)=\tau_{0} \exp \left(\frac{B}{T-T_{0 g}}\right)
$$

where $\Gamma$ is Zeldovitch's factor, $N=N_{A} / V_{m}, J_{c}$ the atom critical number for steady-state nucleation [8]. The value of $\tau^{\text {ns }}$ at the vitreous transition viewed as a crystal homogeneous nucleation temperature is of the order of 100 seconds. The pre-exponential factor $\tau_{0}$ is proportional to $\mathrm{T}_{\mathrm{g}} / \Delta \mathrm{H}_{\mathrm{m}} / \mathrm{V}_{\mathrm{m}} \times \ln \mathrm{K}_{\mathrm{ls}} / \mathrm{K}_{\mathrm{ls}}$ with $\mathrm{T}_{\mathrm{g}} / \Delta \mathrm{H}_{\mathrm{m}}$ being nearly the same in all melts. We deduce that $\ln K_{1 s}$ is equal to $62.5 \pm 2, \ln \mathrm{A}=98.5 \pm 2$ with $\mathrm{B} /\left(\mathrm{T}_{\mathrm{g}}-\mathrm{T}_{0 \mathrm{~g}}\right)=36$ in all undercooled melts at $\mathrm{T}_{\mathrm{g}}^{*}($ see $5-), \mathrm{K}_{\mathrm{ls}}$ and $\mathrm{A}$ in $\mathrm{m}^{-3} \times \mathrm{s}^{-1}$ with $\mathrm{B}=\mathrm{T}_{0 \mathrm{~g}} \times \mathrm{D}^{*}$ in (2) and (6) and $\mathrm{D}^{*}$ the fragility index $[4,20,21]$.

The nucleation temperature $\theta_{21 s}$ occurs not only at a precise value of the energy saving coefficient $\varepsilon_{\mathrm{ls} 0}$ but also when $\ln \mathrm{K}_{\mathrm{ls}}$ becomes equal to $62.5 \pm 2$ [4]; kinetic and thermodynamic effects are combined to produce the vitreous transition; nevertheless, $\theta_{21 \mathrm{~s}}$ may exist without being a vitreous transition when $\mathrm{D}^{*} \mathrm{~T}_{0} /\left(\mathrm{T}_{2 \mathrm{ls}}-\mathrm{T}_{0 \mathrm{~g}}\right)$ cannot be equal to $36, \ln \mathrm{K}_{\mathrm{ls}}$ is much larger than 62.5 in many liquid elements and the viscosity remains too small in spite of an Arrhenius behavior. 


\section{4- Fragile glass-forming melts}

Equations (9) and (10) are applied at $\mathrm{T}=\mathrm{T}_{2 \mathrm{ss}}\left(\right.$ or $\theta=\theta_{2 \mathrm{ls}}$ ); the quadratic equation (12) is obtained:

$$
\frac{\theta_{2 l s}^{2} \varepsilon_{l s 0}}{\theta_{0 l s}^{2}}+3 \theta_{2 l s}+2-\varepsilon_{l s 0}=0
$$

There are two values of $\theta_{21 \mathrm{~s}}$ given in (13) which are solutions of (12) for each value of $\theta_{0 \mathrm{~g}}$ and $\varepsilon_{\mathrm{ls} 0}$ respectively larger than $-2 / 3$ and $1[9,11]$; they correspond to fragile glass-forming melts and are out-of-equilibrium values:

$$
\theta_{2 l s}=\frac{-3 \pm\left[9-4\left(2-\varepsilon_{l s 0}\right) \varepsilon_{l s 0} / \theta_{0 g}^{2}\right]^{1 / 2}}{2 \varepsilon_{l s 0}} \theta_{0 g}^{2}
$$

The minimum value of $\varepsilon_{\mathrm{ls} 0}$ is obtained when (14) and (15) are respected:

$$
\begin{gathered}
\varepsilon_{l s 0}=\varepsilon_{l s}(\theta=0)=1.5 * \theta_{2 l s}+2 \\
\theta_{0 l s}^{2}=\frac{8}{9} \varepsilon_{l s 0}-\frac{4}{9} \varepsilon_{l s 0}^{2}
\end{gathered}
$$

The coefficients $\varepsilon_{\mathrm{lso}}$ of four fragile glass-forming melts $\mathrm{N}^{\circ} 1,2,3$ and 5 are represented in Figure 3 as a function of $\theta_{21 \mathrm{~s}}$ assuming that $\theta_{21 \mathrm{~s}}$ is equal to $\theta_{\mathrm{g}}[22,7,23,5,6]$; the transition at 
equilibrium is given by (14) and represented by a straight line; the various parameters characterizing these melts are given in Table 1.

The ratios $\mathrm{T}^{*} \mathrm{~g} / \mathrm{T}_{0 \mathrm{~g}}$ have been calculated using (14) and (15) and are compared with the experimental results in Table 1 and Figure 4. We assume in the calculation of $\mathrm{T}_{\mathrm{g}}$ that the six melts are fragile. The melts $\mathrm{N}^{\circ} 4$ and $\mathrm{N}^{\circ} 6$ are not following the equations (14) and (15) of fragile melts in spite of the fact that their experimental reduced temperature $\theta_{0 \mathrm{~g}}$ is a little larger than $-2 / 3$. Their vitreous transition is much larger than the expected value for a fragile melt. The experimental values $\mathrm{T}_{0 \mathrm{~g}}$ of $\mathrm{N}^{\circ} 6$ and of $\mathrm{N}^{\circ} 4$ are a little large because of experimental errors. The other melts $\mathrm{N}^{\circ} 1, \mathrm{~N}^{\circ} 2, \mathrm{~N}^{\circ} 3$ and $\mathrm{N}^{\circ} 5$ are fragile; their glass transition corresponds to the thermodynamic transition and to the minimum of $\varepsilon_{1 \mathrm{~s} 0}$ represented in figure 3. A glass transition of $622 \mathrm{~K}$ and an energy saving coefficient $\varepsilon_{\mathrm{ls} 0}=1.229$ are calculated from (13) with $\mathrm{T}_{0 \mathrm{~g}}=356 \mathrm{~K}$ which corresponds to $\theta_{0 \mathrm{~g}}=-2 / 3$ assuming that the melt $\mathrm{N}^{\circ} 6$ is strong. The same ratio $\mathrm{T}_{\mathrm{g}} / \mathrm{T}_{0 \mathrm{~g}}$ is plotted as a function of $\theta_{0 \mathrm{~g}}$ in Figure 5; it strongly varies when $\theta_{0 \mathrm{~g}}$ is very close to $-2 / 3$. The vitreous transition of fragile liquids tends to be equal to the free-volume disappearance temperature.

The fragile liquids have an equilibrium homogeneous nucleation temperature $\theta_{21 \mathrm{~s}}$ that only depends on $\varepsilon_{\mathrm{ls} 0}$ and does not strictly depend on $\ln \mathrm{K}_{\mathrm{ls}}$ and then on the viscosity even if $\ln K_{1 s}$ has a value nearly equal to 62.5 at this temperature. The kinetic character of the vitreous transition $\theta_{2 \mathrm{~s}}=\theta^{*} \mathrm{~g}$ is accompanying the thermodynamic vitreous transition at equilibrium because the freezing of atom freedom degrees is produced by a well-defined value of $\ln K_{\mathrm{ls}}$ which is $\mathrm{T}^{*}{ }_{\mathrm{g}}$ dependent through $\left[\mathrm{D}^{*} \mathrm{~T}_{\mathrm{og}} /\left(\mathrm{T}^{*} \mathrm{~g}_{\mathrm{g}}-\mathrm{T}_{0 \mathrm{~g}}\right)\right]$ and also through $\ln \mathrm{A}$.

\section{5- Strong glass-forming melts}


The energy saving coefficient $\varepsilon_{1 s 0}$ of strong glass-forming melts is calculated using (13) when $\theta_{2 l \mathrm{~s}}=\theta *_{\mathrm{g}}$ and $\theta_{0 \mathrm{~g}}<-2 / 3$ are known. There is a boundary $\theta_{0 \mathrm{~g}}=-2 / 3\left(\right.$ or $\mathrm{T}_{0 \mathrm{~g}}=\mathrm{T}_{\mathrm{m}} / 3$ ) that separates strong and fragile undercooled liquids in Angell's classification [20]. The coefficient $\varepsilon_{\mathrm{ls} 0}$ is calculated with (13) and is plotted in Figure 6 as a function of $\theta^{*} \mathrm{~g}=\left(\mathrm{T}^{*} \mathrm{~g}^{-}\right.$ $\left.T_{m}\right) / T_{m}$ for various values of $\theta_{0 \mathrm{~g}}$. It varies from 0.217 , which is the energy saving coefficient of liquids elements, up to 2 . The nucleation reduced temperature $\theta *_{\mathrm{g}}$ increases from $-2 / 3$ up to zero and corresponds to many possible values of the vitreous transition. It has been shown that $T_{g}$ strongly depends on the heating rates; the homogeneous nucleation temperature $\theta_{0 \mathrm{~g}}$ can exist without leading to a vitreous transition because $\ln K_{1 s}$ in (6) is not always equal to equal to 62.5 [4-6].

The largest values of $\varepsilon_{\mathrm{ls} 0}$ correspond in Figure 6 to fragile melts and are aligned on a straight line while the $\varepsilon_{1 \mathrm{~s} 0}$ of strong melts is smaller and decreases when $\theta_{0 \mathrm{~g}}$ tends to -1 with the increase of the Arrhenius character of the VFT law. Liquids are called strong because they are more resistant to structural change than fragile liquids [20]. The VFT temperature of fragile glasses near the maximum of $\mathrm{T}_{\mathrm{g}} / \mathrm{T}_{0 \mathrm{~g}}$ is equal to about $0.65 \times \mathrm{T}_{\mathrm{g}}$ and increases up to $0.77 \times \mathrm{T}_{\mathrm{g}}$ at higher temperatures while $-0.5 \times \theta_{\mathrm{g}}$ has to be added to $\varepsilon_{\mathrm{ls} 0}\left(\theta_{\mathrm{g}}\right)$ [4]. These changes of the VFT temperature and the energy saving also characterize the fragile liquids and would be related to a decrease of the Fermi energy difference between crystal and melt when the temperature decreases. This change could be present or absent in the strong ones.

The thermodynamic vitreous transition $\mathrm{T}_{\mathrm{g}}$ of a strong melt continuously increases with $\varepsilon_{\mathrm{ls} 0}$ for a given value of $\theta_{0 \mathrm{~g}}$ as shown in figure 6 . A strong glass has a relaxation time which follows a VFT law around the vitreous transition [6]. The true $\mathrm{T}_{\mathrm{g}} \mathrm{g}$ can be determined by studying the thermal variation of the fully-relaxed enthalpy and the value of $\varepsilon_{\text {ls } 0}$ can be 
deduced from the knowledge of $\mathrm{T}^{*}{ }_{\mathrm{g}}$ and $\mathrm{T}_{0 \mathrm{~g}}$ using (13). A unique value of $\mathrm{T}_{\mathrm{g}}$ is also expected in each strong melt in spite of the existence of many possible homogeneous nucleation temperatures because $\mathrm{T}_{\mathrm{g}}$ is probably fixed by a unique and universal value of viscosity at this temperature.

\section{6- Is the viscosity a universal quantity accompanying the vitreous transition?}

The thermodynamic vitreous transition $\mathrm{T}_{\mathrm{g}}$ of a strong melt continuously increases with $\varepsilon_{\mathrm{ls} 0}$ for a given value of $\theta_{0 \mathrm{~g}}$ as shown in Figure 6 . A strong glass has a relaxation time which follows a VFT law around the vitreous transition [6]. The true $\mathrm{T}^{*} \mathrm{~g}$ can be determined by studying the thermal variation of the fully-relaxed enthalpy and the value of $\varepsilon_{1 \mathrm{~s} 0}$ can be deduced from the knowledge of $\mathrm{T}^{*} \mathrm{~g}$ and $\mathrm{T}_{0 \mathrm{~g}}$ using (13). A unique value of $\mathrm{T}^{*} \mathrm{~g}$ is then expected in each strong melt in spite of the existence of many possible homogeneous nucleation temperatures because $\mathrm{T}^{*} \mathrm{~g}$ is probably fixed by a unique and universal value of viscosity at this temperature.

\section{7- The fragility indexes of strong and fragile liquids}

The relation (16) is used to calculate the fragility indexes which results from the fact that $\left[\mathrm{D}^{*} \mathrm{~T}_{\mathrm{og}} /\left(\mathrm{T}^{*}{ }_{\mathrm{g}}-\mathrm{T}_{0 \mathrm{~g}}\right)\right]$ is considered, up to now, as being equal to $36-39[20,21]$. The constant 36 is used to calculate the fragility indexes of liquids when $T_{g} / T_{0 g}$ is known; It is deduced from the average value of the proportionality coefficient of $D^{*}$ with $\left(T^{*} / T_{0 g}-1\right)$ [22]: 


$$
\frac{T^{*}}{T_{0 g}} \cong 1+\frac{D^{*}}{36}
$$

The ratio $\mathrm{T}_{\mathrm{g}} / \mathrm{T}_{0 \mathrm{~g}}$ of strong and fragile liquids is calculated using (13) and (14) respectively. The fragility indexes of fragile and strong liquids deduced from (16) are plotted as a function of $\varepsilon_{\mathrm{ls} 0}$ in Figure 7. A unique value of $\mathrm{D}^{*}$ or $\mathrm{T}^{*}{ }_{\mathrm{g}} / \mathrm{T}_{0 \mathrm{~g}}$ corresponds to $\varepsilon_{\mathrm{ls} 0}$ in fragile liquids while an infinity of values of $\mathrm{D} *$ and $\mathrm{T} * \mathrm{~g} / \mathrm{T}_{0 \mathrm{~g}}$ corresponds in strong liquids to each value of $\varepsilon_{\mathrm{ls} 0}$. This point has been already discussed in 5-.

\section{8- The energy saving and the Laplace pressure associated with clusters in melts}

It has been already recognized that a volume energy equal $-\left(\mathrm{p}-\mathrm{p}_{0}\right) \times \mathrm{V}_{\mathrm{m}}$ has to be added to the classical Gibbs free energy change $\theta \times \Delta \mathrm{H}_{\mathrm{m}} / \mathrm{V}_{\mathrm{m}}$ associated with cluster formation in melts in order to reflect the presence of inhomogeneous pressure due to the Laplace pressure $p$ acting on compressible out-of-equilibrium clusters. This proposal can be applied to cluster formation in nonmetallic liquids. In our case, the Fermi energy difference depends on temperature and progressively disappears when the free volume of the melt tends to zero. We have already shown that the saving energy of titanium clusters per mole at the melting temperature $T_{m}$ is equal to $\left(p-p_{o}\right) V_{m}$ where $p$ is the Laplace pressure and $p_{0}$ the pressure of the melt where $p$ is defined by $p=2 \times \sigma / R *{ }_{21 s}, \sigma$ being the cluster surface energy and $R *_{21 s}$ the critical radius. The pressure $\mathrm{p}$ can be calculated from $(3,8)$ and we obtain (17):

$$
p=\frac{2 \times \sigma}{R_{2 l s}^{*}}=\frac{\Delta H_{m}}{V_{m}}\left[\theta-\varepsilon_{l s}(\theta)\right] .
$$


The product $\left(\mathrm{p}-\mathrm{p}_{0}\right) \times \mathrm{V}_{\mathrm{m}}=\Delta \mathrm{p} \times \mathrm{V}_{\mathrm{m}}$ is equal to the saving energy per mole and $\mathrm{p}_{0}=\theta \times \Delta \mathrm{H}_{\mathrm{m}} / \mathrm{V}_{\mathrm{m}}$ is the classical contribution which does not depend on the free volume. The energy saving $\varepsilon_{\mathrm{ls}} \times \Delta \mathrm{H}_{\mathrm{m}} / \mathrm{V}_{\mathrm{m}}$ is also the change in the Laplace pressure that we have introduced in (3) ignoring that D. T. Wu, L. Granasy and F. Spaepen had already suggested that an energy $-\left(p-p_{o}\right) V_{m}$ ought to be added in the classical equation of the Gibbs free energy change for a crystal formation [14]. The Laplace pressure change $\Delta \mathrm{p}$ tends to zero with the cluster radius and with the free volume not only in metallic glass-forming melts but also in nonmetallic glassforming melts because the equations (9) and (10) are followed by the two types of melts $[4,15]$.

\section{9- Conclusion}

The vitreous transition temperature $\mathrm{T}^{*} \mathrm{~g}$ has been recently viewed as a material constant which is equal to the crystal homogeneous nucleation temperature in glass-forming melts. This result has been obtained by adding a volume energy saving $\varepsilon_{\mathrm{v}}$ per volume unit to the classical Gibbs free energy change $\theta \times \Delta \mathrm{H}_{\mathrm{m}} / \mathrm{V}_{\mathrm{m}}$ for a crystal formation in a melt. We have shown that $\varepsilon_{\mathrm{v}}$ is equal to the experimental Laplace pressure change (p- $\left.\mathrm{p}_{0}\right)$ as compared to the classical pressure $\mathrm{p}_{0}=\theta \times \Delta \mathrm{H}_{\mathrm{m}} / \mathrm{V}_{\mathrm{m}}$ acting on crystals imbedded in a melt. It is now easier to understand why this model also works for nonmetallic glass-forming melts because such inhomogeneous pressure is acting on all crystals having a radius smaller or equal to the critical one.

We have also shown that the model is able to strictly predict the precise value of the Vogel-Fulcher-Tamman temperature, the energy saving $\varepsilon_{\mathrm{v}}$ and the ratio $\mathrm{T}_{\mathrm{g}}^{*} / \mathrm{T}_{0 \mathrm{~g}}$ of fragile liquids when the equilibrium transition temperature $\mathrm{T}_{\mathrm{g}}^{*}$ is known. These predictions are not 
possible in strong liquids because there are a lot of possible values of $\mathrm{T}^{*} \mathrm{~g}$ when the VFT temperature $T_{0 \mathrm{~g}}$ is known. The viscosity at $\mathrm{T}^{*} \mathrm{~g}$ has to be fixed to determine $\mathrm{T}_{0 \mathrm{~g}}$. The fragility indexes of fragile glasses and the map of fragility indexes of strong liquids depending on the $\mathrm{T}_{\mathrm{g}}^{*}$ and $\mathrm{T}_{0 \mathrm{~g}}$ have been calculated as a function of $\mathrm{T}_{\mathrm{g}}$.

The vitreous transition temperature $\mathrm{T}_{\mathrm{g}}$ of all glass-forming melts strictly depends on a precise value of the energy saving at the melting temperature and is accompanied by a freezing of supplementary freedom degrees of atoms in melts as compared to those in crystals. This whole freezing is probably produced by a universal value of the liquid viscosity accompanying the preliminary step of transient nucleation leading to crystallization at unattainable times.

\section{Acknowledgments}

This work was sponsored by the Laboratory for the Application of Superconductors and Magnetic Materials involving the Northwest Institute for Non-ferrous Metal Research (NIN), the Northwestern Polytechnical University (NPU) in Xi'an (P.R. China). Thanks are due to Lian Zhou for NIN support as, Dr Jinna Mei from NPU and J.L. Soubeyroux from CNRS/CRETA for their study of relaxed enthalpy of some glass-forming melts [26].

\section{References}

[1] Holubovà, J., Cernozek, Z., Cernoskovà E. J. Optoelectron. Adv. Mat. 2005;7: 26712676.[2] Cernosek, Z., Holubova, J., Cernoskova E. J. Optoelectron. Adv. Mater. 2005;7:2941-2944.

[3] Cernosek, Z., Holubova, J., Cernoskova E., Liska, M. J. Optoel. Adv. Mater. 2002;4:489503.

[4] Tournier R. Materials 2011;4:869-892.

[5] Busch R., Liu W., Johnson W.L. J. Appl. Phys. 1998;83:4134-4441. 
[6] Busch, R. Bakke E., Johnson, W.L. Acta Metall. 1998;46:4725-4732.

[7] Waniuk T.A., Busch R. Masuhr A. Johnson W.L. Acta Mater. 1998;46:5229-5236.

[8] Gutzov I., Schmeltzer J. The Vitreous State, Ed. Springer-Verlag, Berlin 1995.

[9] Tournier R.F. Sci. Technol. Adv. Mater. 2009;10:014607:1-12. http://stacks.iop.org/14686996/10/014607.

[10] Tournier R.F Physica B 2007;392:79-93.

[11] Tournier R.F. J. Phys: Conference Series 2009;144:012116:1-4.

[12] Tournier R. F. Progress in Light Metals, Aerospace Mater. Supercond. eds Y Lu, P. Zhang, C Jiang and Y Han, Trans Tech Publ. 2007;4:1827-1840.

[13] Tournier R. F. Vth Int. Symp. Electromagn. Process. Mater. Ed S Taniguchi, Iron Steel Inst, Japan, 2006,561-567.

[14] D. T. Wu, L. Granasy, and F. Spaepen, MRS Bulletin, 2004;December:945-950 http://www.mrs.org/publications/bulletin.

[15] Tournier R. F. Proceedings of the 12th world conference on titanium (2011), to be published.

[16] Tournier R.F. Proceedings of the 6th International Conference on Electromagnetic Processing of Materials, EPM 2009, Ed: Forschungszentrum Dresden-Rossendorf, Germany, 2009, 304-307.

[17] Doolittle A. K. J. Appl. Phys. 1951; 22:1471-1475.

[18] Vinet B., Magnusson L., Fredriksson H., Desré P.J. J. Coll. Interf. Sci. 2002;255:363374.

[19] Turnbull D., Fisher, J. C. J. Chem. Phys. 1949;17:71-73

[20] C. A. Angell, Science, 1995;267:1924-1935.

[21] Takeuchi, A., Kato H., Inoue A. Intermetallics 2010;18:406-411.

[22] Schroers J. Acta Mater. 2008;56:471-478.

[23] Gallino I., Shah M.B., Busch R., Acta Mater. 2007;55:1367-1376.

[24] Fan G. J., Fecht H. J., Lavernia E.J. Appl.Phys. Lett. 2004;84;84:487-9

[25] Mukherjee S., Schroers S., Zhou Z., Johnson W. L., Rhim W. K. Acta Mater.

2004;52:3689-95.

[26] Mei, J.N., Soubeyroux, J.L.; Blandin, J.J., Li, J.S., Kou, H.C. , Fu, H.Z., Zhou L.

Structural relaxation of $\mathrm{Ti}_{40} \mathrm{Zr}_{25} \mathrm{Ni}_{8} \mathrm{Cu}_{9} \mathrm{Be}_{18}$ bulk metallic glass. J. Non-Cryst. Sol. 2011, 357, 110-115. 


\section{Figure and Table Captions}

Figure 1: The specific heat difference between liquid and vitreous states is plotted versus temperature. The undercooled liquid is quenched down to $\mathrm{B}$ at a temperature $\mathrm{T}_{\mathrm{g} 1}$ smaller than the thermodynamic transition $\mathrm{T}_{\mathrm{g}}$. The transformation time from the quenched undercooled melt to the vitreous state is equal to the relaxation time and occurs from $\mathrm{B}$ to $\mathrm{C}$ at $\mathrm{T}_{\mathrm{g} 1}$ accompanied by an exothermic heat equal to the surface $\mathrm{ABCD}$. The sample is rapidly heated up to E; the transformation time from the vitreous to the liquid state is equal to the relaxation time at the temperature $\mathrm{T}_{\mathrm{g} 2}$ and the endothermic heat is equal to the surface ADEF.

Figure 2: The ratio $\Delta \mathrm{G}^{*}{ }_{21 \mathrm{~s}} / \mathrm{k}_{\mathrm{B}} \mathrm{T} / \mathrm{lnK}_{\mathrm{ls}}$ given by (7) is plotted versus $\theta=\left(\mathrm{T}-\mathrm{T}_{\mathrm{m}}\right) / \mathrm{T}_{\mathrm{m}}$ down to $\theta=\theta_{2 \mathrm{ls}}$ when $\varepsilon_{\mathrm{ls} 0}$ given by (9) is equal to $1.8,1.6,1.4,1.2$ and 1 . It is always equal to 1 far above the homogeneous nucleation temperature $\theta_{21 s}$.

Figure 3: The minimum value of the energy saving coefficient $\varepsilon_{\mathrm{ls} 0}$ at the melting temperature $T_{\mathrm{m}}$ follows the linear equation $\varepsilon_{\mathrm{ls} 0}=1.5 \times \theta_{\mathrm{g}}+2$ as a function of $\theta_{21 \mathrm{~s}}=\theta_{\mathrm{g}}=\left(\mathrm{T}_{\mathrm{g}^{-}}\right.$ $\left.\mathrm{T}_{\mathrm{m}}\right) / \mathrm{T}_{\mathrm{m}}$. The other values of $\theta_{2 \mathrm{~s}}$ are also solutions of (12). The melts $\mathrm{N}^{\circ} 1,2,3$ and 5 are respectively $\quad \mathrm{Pd}_{43} \mathrm{Ni}_{10} \mathrm{Cu}_{27} \mathrm{P}_{20}, \quad \mathrm{Zr}_{41.2} \mathrm{Ti}_{13.8} \mathrm{Cu}_{12.5} \mathrm{Ni}_{10} \mathrm{Be}_{22.5}, \quad \mathrm{Zr}_{58.5} \mathrm{Cu}_{15.6} \mathrm{Ni}_{12.8} \mathrm{Al}_{10.3} \mathrm{Nb}_{2.8}$ and $\mathrm{Zr}_{65} \mathrm{Al}_{10} \mathrm{Ni}_{10} \mathrm{Cu}_{15}$. Their properties are given in Table 1 .

Figure 4: The theoretical values of $\mathrm{T}_{\mathrm{g}}$ divided by $\mathrm{T}_{0 \mathrm{~g}}$ noted $\mathrm{A}$ are plotted versus the theoretical value of $\theta_{\mathrm{g}}$. Experimental values of $\mathrm{T}_{0 \mathrm{~g}}$ have been used to calculate the theoretical values of $\mathrm{T}^{*} \mathrm{~g} / \mathrm{T}_{0 \mathrm{~g}}$ noted $\mathrm{B}$ and given in Table 1 assuming that these melts are fragile. The 
points noted $\mathrm{C}$ are the experimental values $\mathrm{T}_{\mathrm{g}} / \mathrm{T}_{0 \mathrm{~g}}$. The following melts $\mathrm{Mg}_{65} \mathrm{Cu}_{25} \mathrm{Y}_{10}$ and $\mathrm{Zr}_{46.75} \mathrm{Ti}_{8.25} \mathrm{Cu}_{7.5} \mathrm{Ni}_{10} \mathrm{Be}_{27.5}$ would be strong with a smaller value of $\mathrm{T}_{0 \mathrm{~g}}$.

Figure 5: The theoretical values of $\mathrm{T}^{*}{ }_{\mathrm{g}}$ divided by $\mathrm{T}_{0 \mathrm{~g}}$ noted $\mathrm{A}$ are plotted versus $\theta_{0 \mathrm{~g}}$. The experimental quantities $\mathrm{T}^{*} \mathrm{~g} / \mathrm{T}_{0 \mathrm{~g}}$ noted $\mathrm{B}$ and given in table 1 are plotted versus $\theta_{0 \mathrm{~g}}$ instead of $\theta_{\mathrm{g}}$ in Figure 4 . This diagram shows that $\mathrm{T}_{\mathrm{g}} / \mathrm{T}_{0 \mathrm{~g}}$ in fragile liquids is strongly varying near $\theta_{0 \mathrm{~g}}=-2 / 3$. Any experimental uncertainty on $\mathrm{T}_{0 \mathrm{~g}}$ leads to a large variation of $\mathrm{T}_{\mathrm{g}}^{*}$. The points noted $\mathrm{C}$ correspond to the experimental values $\mathrm{T}_{\mathrm{g}} / \mathrm{T}_{0 \mathrm{~g}}$. The following melts $\mathrm{Mg}_{65} \mathrm{Cu}_{25} \mathrm{Y}_{10}$ and $\mathrm{Zr}_{46.75} \mathrm{Ti}_{8.25} \mathrm{Cu}_{7.5} \mathrm{Ni}_{10} \mathrm{Be}_{27.5}$ could be strong with a value of $\mathrm{T}_{0 \mathrm{~g}}$ being a little smaller.

Figure 6: The energy saving coefficient $\varepsilon_{\mathrm{ls} 0}$ of fragile melts is represented by a straight line as a function of $\theta_{\mathrm{g}}^{*}=\left(\mathrm{T}^{*} \mathrm{~g}_{\mathrm{m}} \mathrm{T}_{\mathrm{m}}\right) / \mathrm{T}_{\mathrm{m}}$. Its lowest value 0.217 corresponds to liquid elements. Each curve corresponds to values of $\theta^{*}{ }_{\mathrm{g}}$ equal to $-2 / 3,-0.7,-0.8,-0.9$ and -1 .

Figure 7: The fragility indexes of fragile glasses are distributed along an arc. Strong liquid indexes are calculated for various values of $\theta_{0 \mathrm{~g}}:-2 / 3,-0.7,-0.8-0.9$ and -1 .

Table 1: The references for the VFT temperatures $\mathrm{T}_{0 \mathrm{~g}}$ are: [22 ] for $\mathrm{N}^{\circ} 1$, [7] for $\mathrm{N}^{\circ} 2$, [23] for $\mathrm{N}^{\circ} 3$, [5] for $\mathrm{N}^{\circ} 4$, [22] for $\mathrm{N}^{\circ} 5$ and [6] for $\mathrm{N}^{\circ} 6$. The energy saving coefficients $\varepsilon_{\mathrm{ls} 0}$ and $\mathrm{T}^{*} \mathrm{~g}$ are calculated with (14) and (15) using the experimental value $\mathrm{T}_{0 \mathrm{~g}}$ considering that all these undercooled melts could be fragile; $\mathrm{T}_{\mathrm{g}}$ or $\theta^{*_{\mathrm{g}}}$ is the thermodynamic transition temperature of fragile melts; the ratios $\mathrm{T}_{\mathrm{g}} / \mathrm{T}_{\mathrm{og}}$ are indicated as a function of $\theta^{*}{ }_{\mathrm{g}}=\left(\mathrm{T}^{*} \mathrm{~g}^{-}\right.$ $\left.T_{m}\right) / T_{m}$; the temperature $T_{g}$ is the experimental transition temperature. The experimental ratios $\mathrm{T}_{\mathrm{g}} / \mathrm{T}_{0 \mathrm{~g}}$ can be compared to the theoretical ones $\mathrm{T}^{*} \mathrm{~g} / \mathrm{T}_{\mathrm{og}}$. The experimental fragility indexes $\mathrm{D}^{*}$ are given in the last column. 
Figure 1
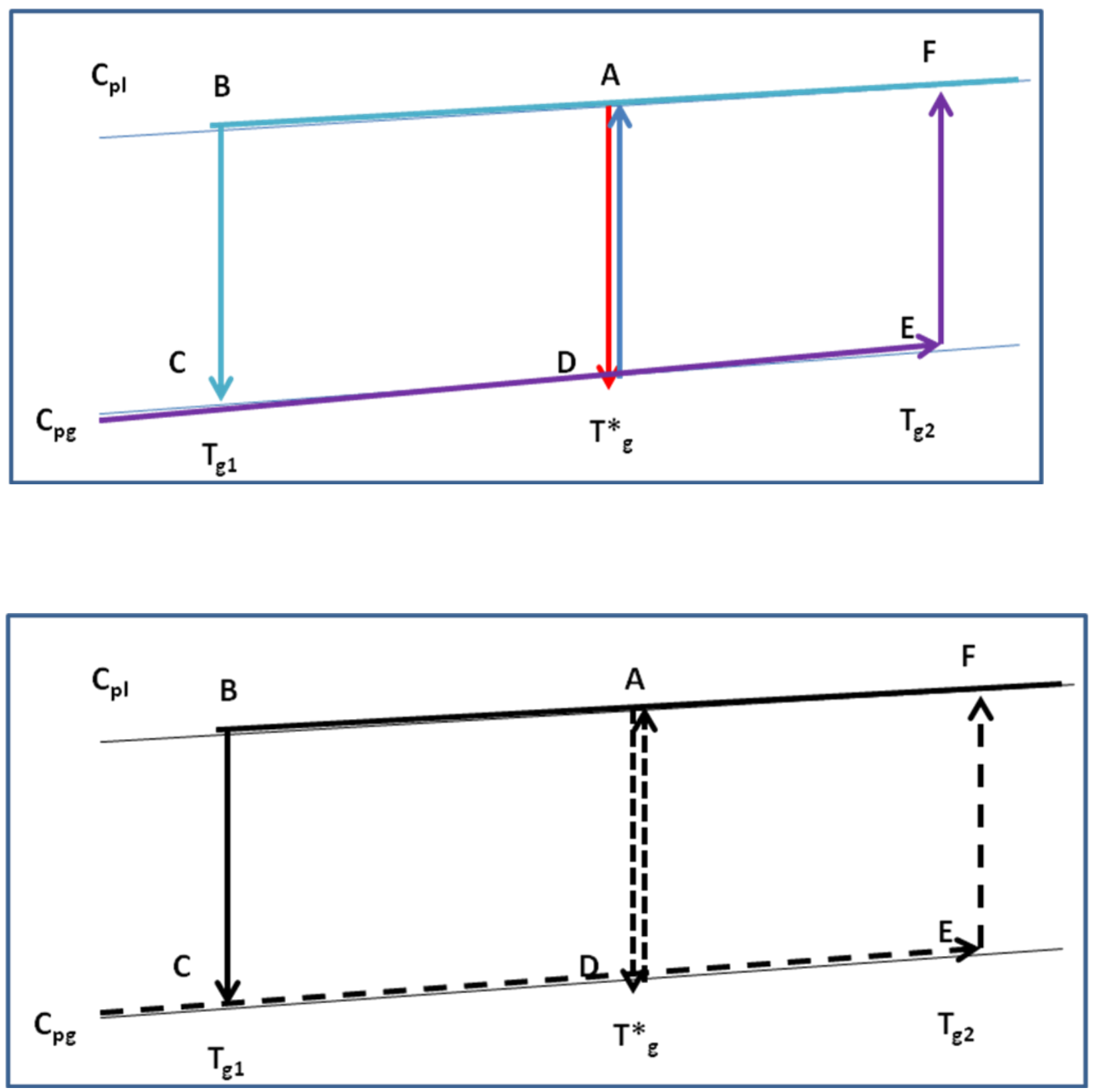
Figure 2
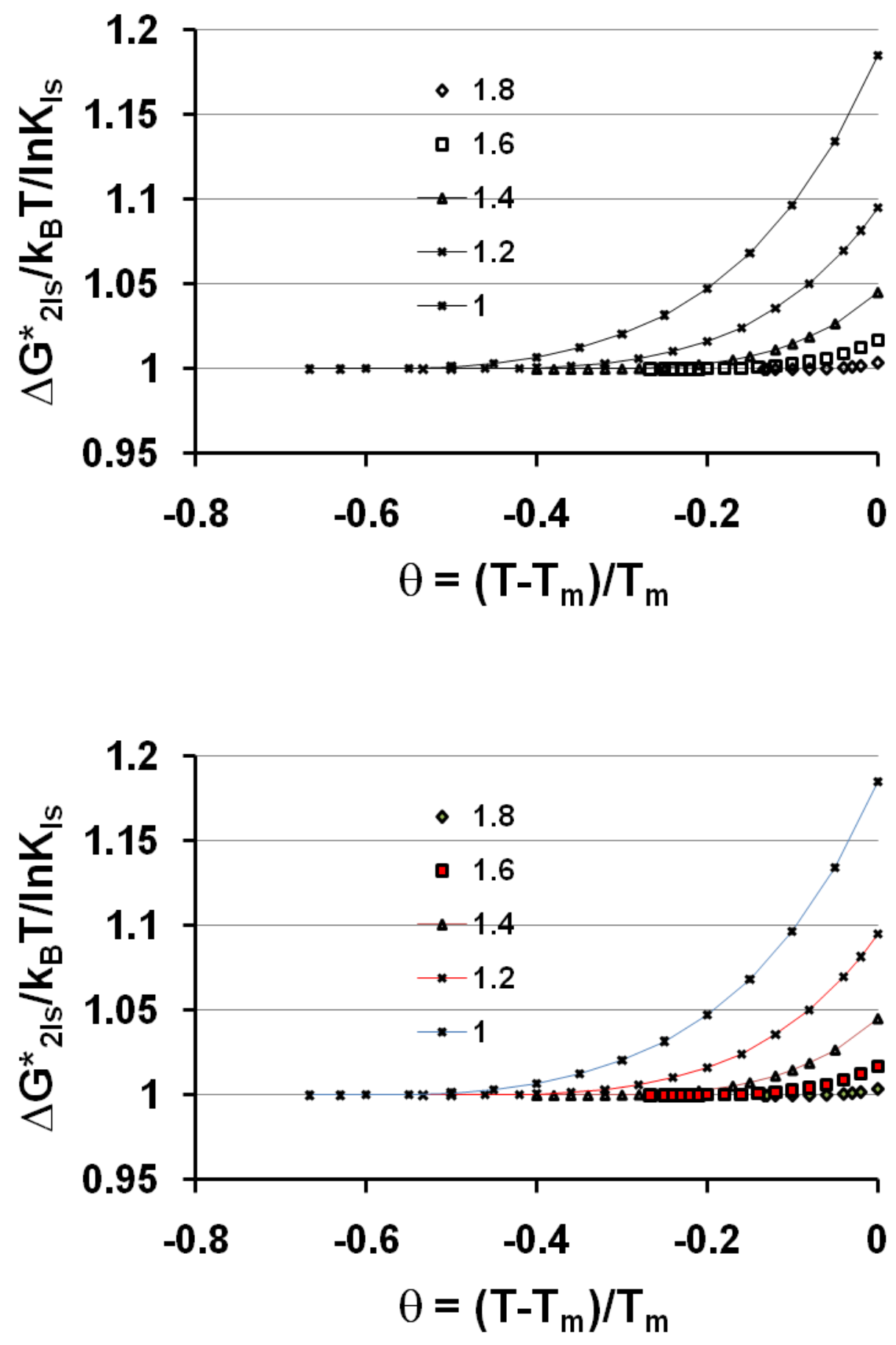
Figure 3
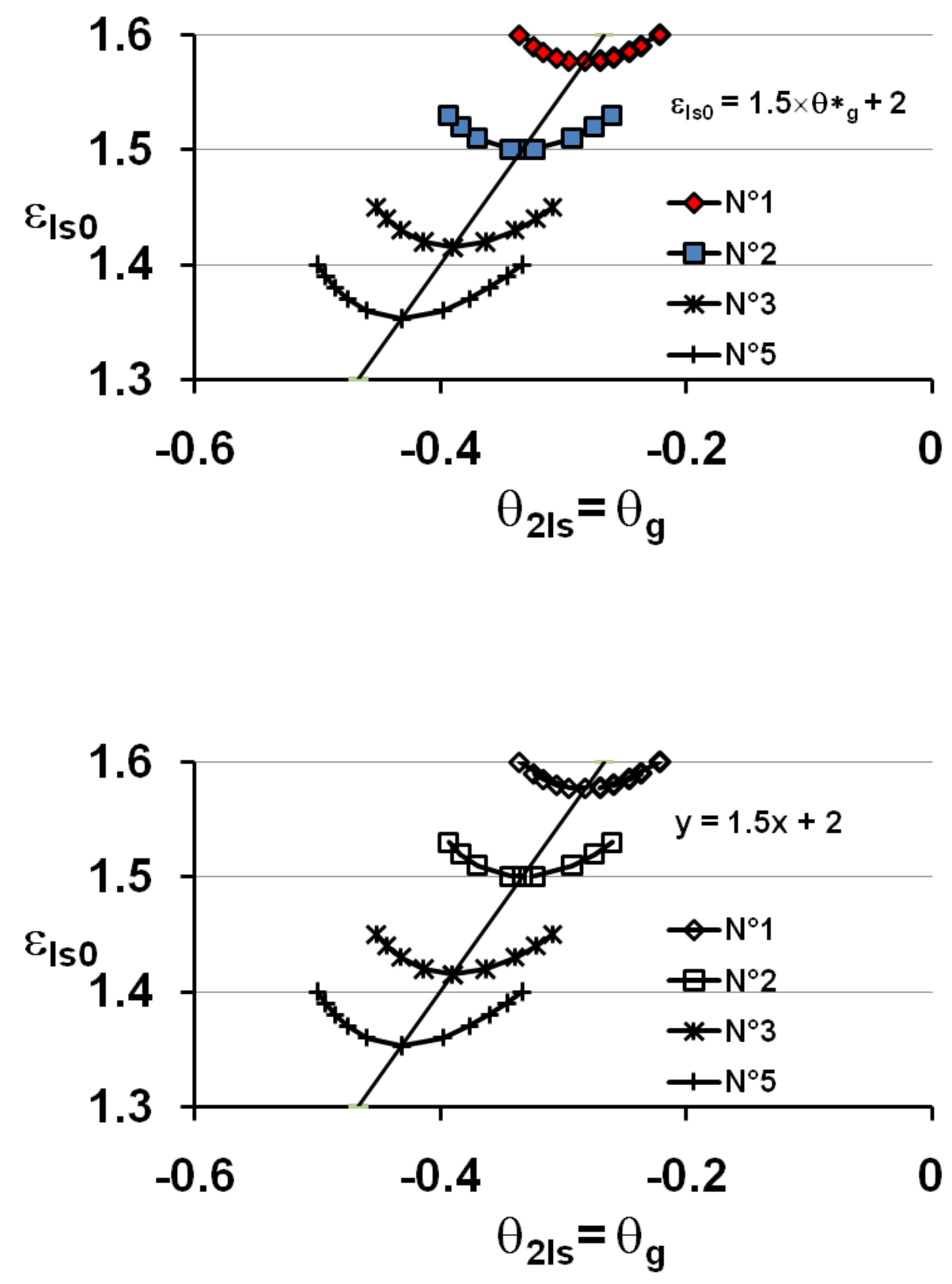
Figure 4
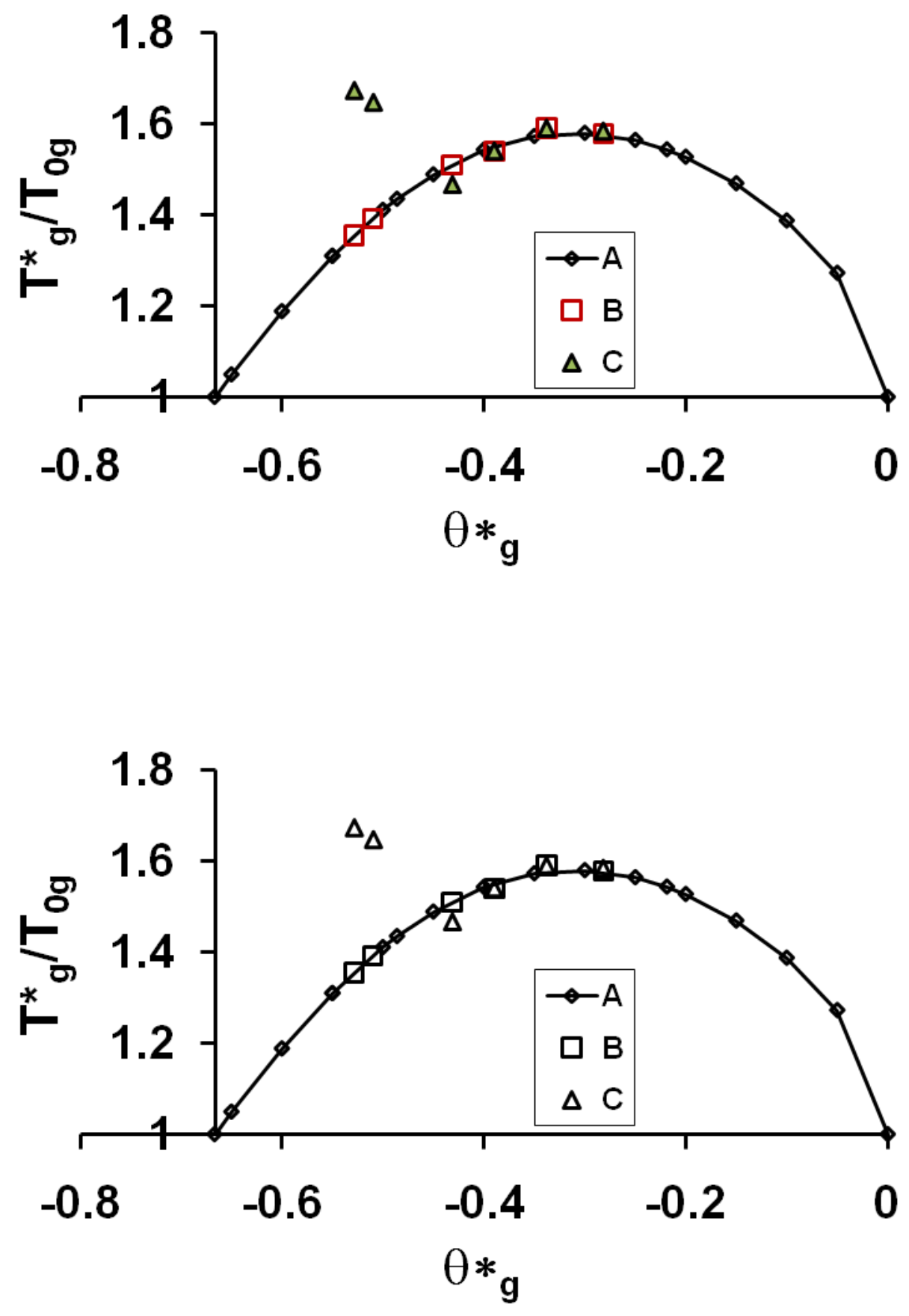
Figure 5

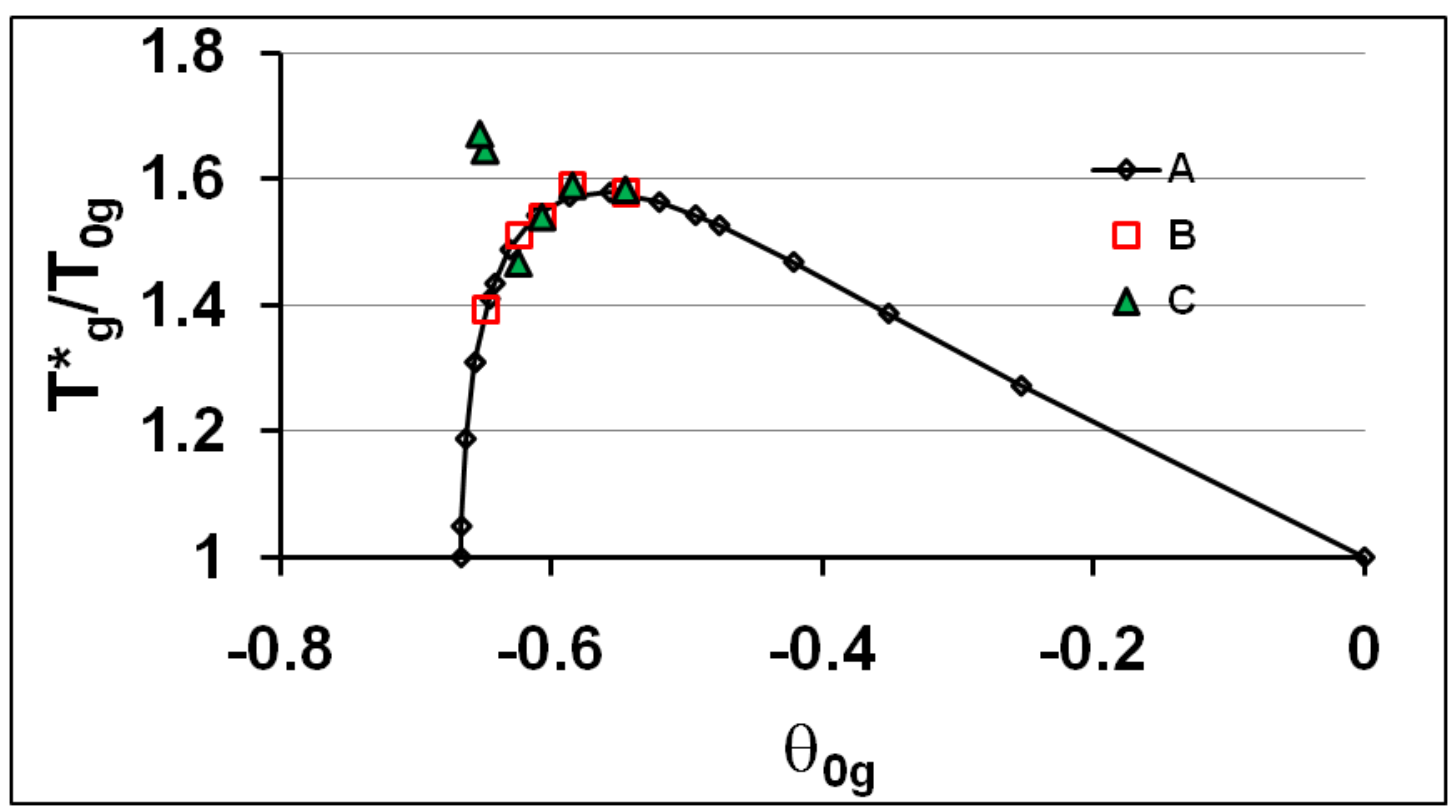




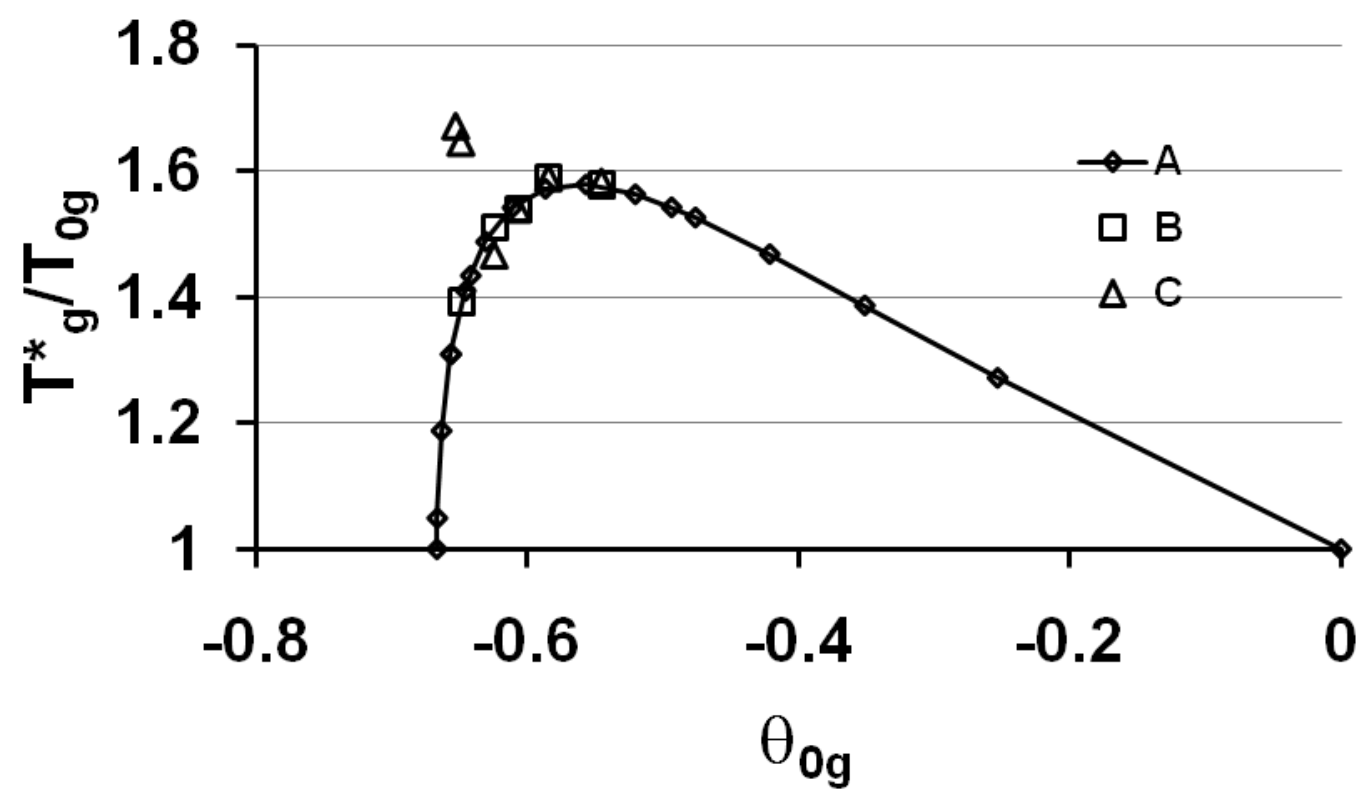

Figure 6

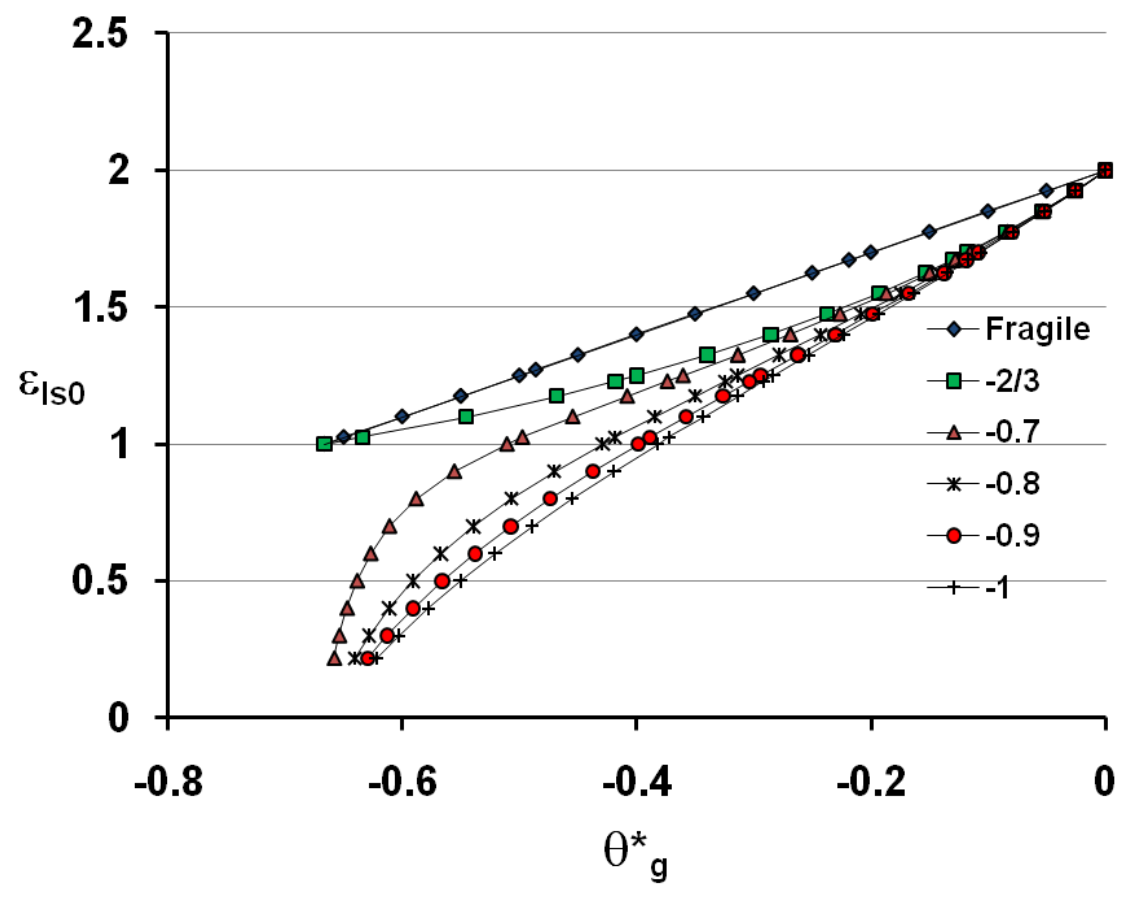




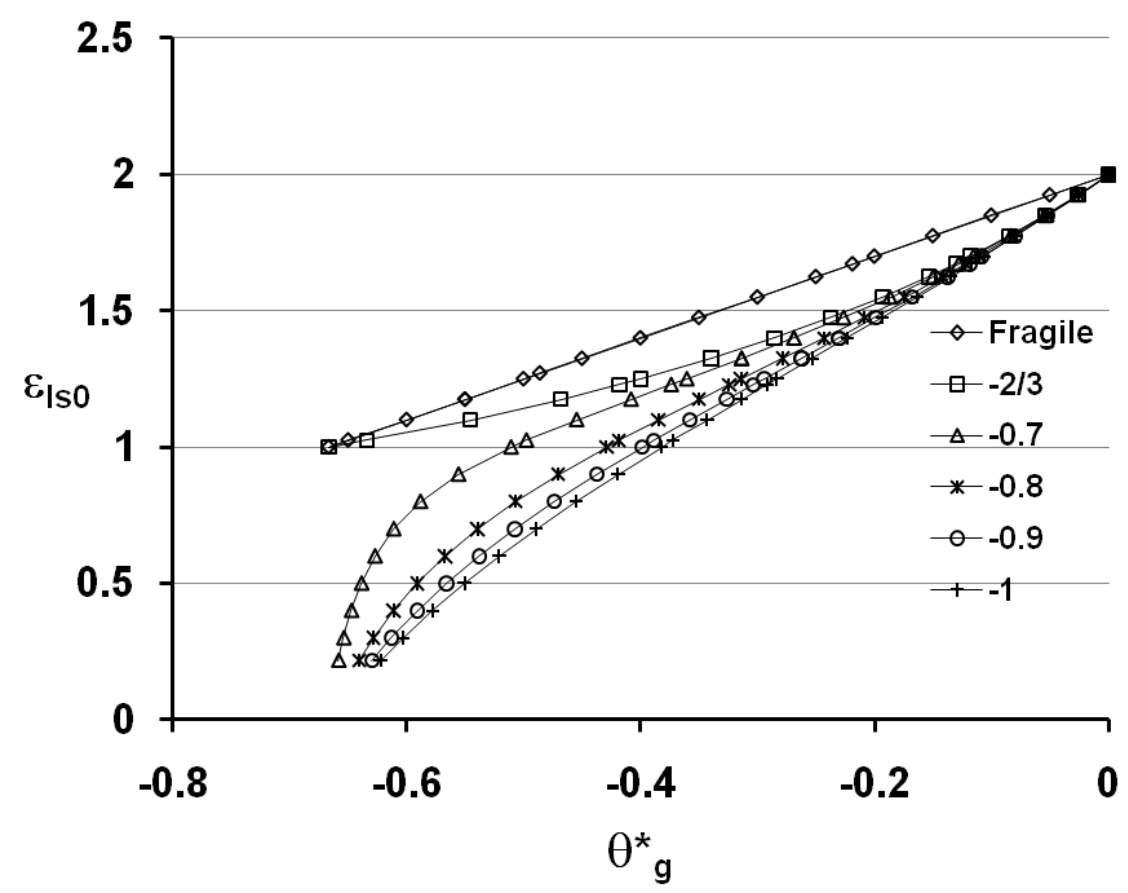

Figure 7

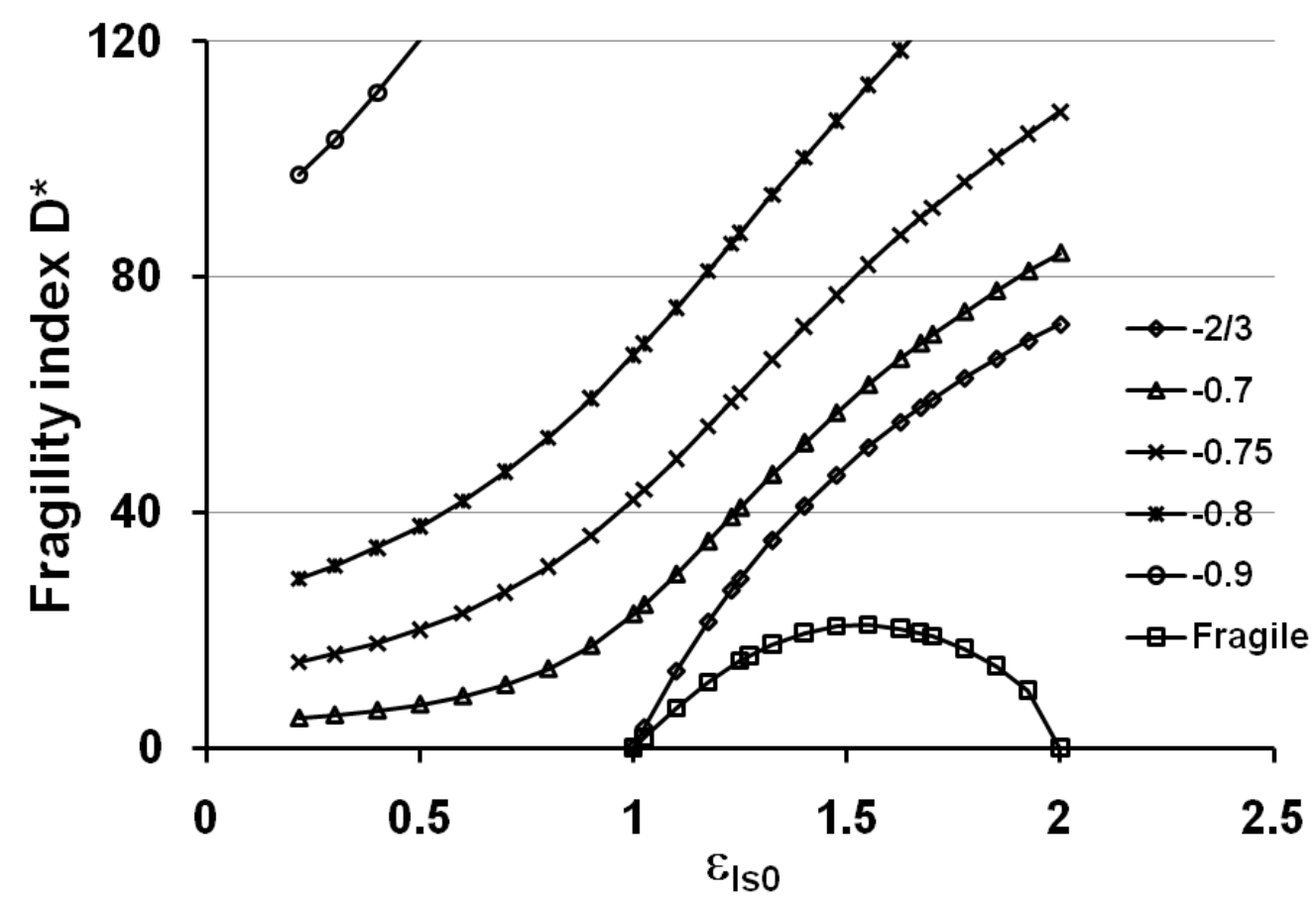




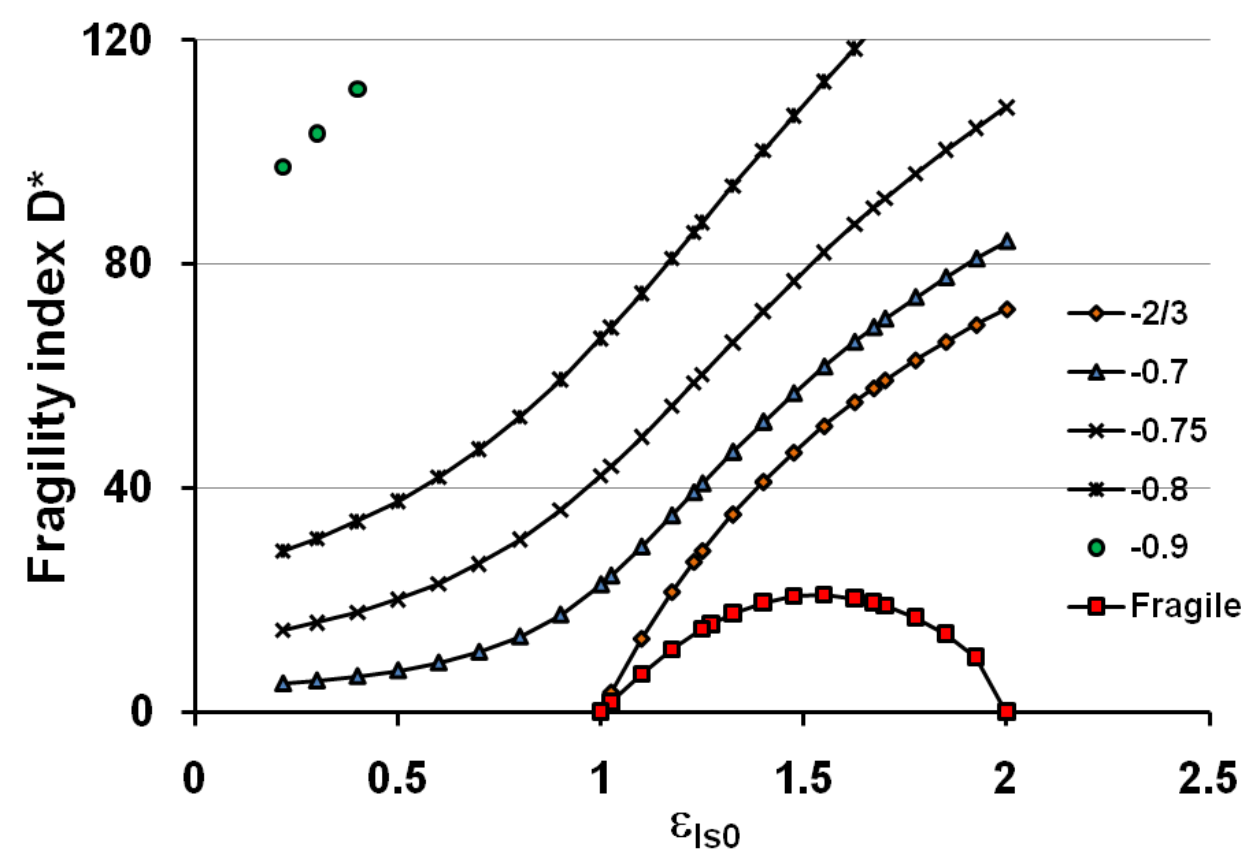

Table 1

\begin{tabular}{|l|l|l|l|l|l|l|l|l|l|l|l|}
\hline $\mathrm{N}^{\circ}$ & melt & $\mathrm{T}_{\mathrm{m}}$ & $\mathrm{T}_{0 \mathrm{~g}}$ & $\varepsilon_{\mathrm{ls} 0}$ & $\mathrm{~T}_{\mathrm{g}}$ & $\theta_{\mathrm{g}}$ & $\mathrm{T}_{\mathrm{g}} / \mathrm{T}_{0 \mathrm{~g}}$ & $\mathrm{~T}_{\mathrm{g}}$ & $\mathrm{T}_{\mathrm{g}} / \mathrm{T}_{0 \mathrm{~g}}$ & $\mathrm{D}^{*}$ & ref \\
\hline 1 & $\mathrm{Pd}_{43} \mathrm{Ni}_{10} \mathrm{Cu}_{27} \mathrm{P}_{20}$ & 802 & 365 & 1.577 & 576 & -0.545 & 1.58 & 578 & 1.58 & & {$[24,22]$} \\
\hline 2 & $\mathrm{Zr}_{41.2} \mathrm{Ti}_{13.8} \mathrm{Cu}_{12.5} \mathrm{Ni}_{10} \mathrm{Be}_{22.5}$ & 937 & 396 & 1.501 & 625 & -0.577 & 1.58 & 622 & 1.57 & 23.8 & {$[25,22]$} \\
\hline 253 & $\mathrm{Zr}_{58.5} \mathrm{Cu}_{15.6} \mathrm{Ni}_{12.8} \mathrm{Al}_{10.3} \mathrm{Nb}_{2.8}$ & 1110 & 437 & 1.415 & 673 & -0.606 & 1.54 & 673 & 1.51 & 19.7 & {$[23,22]$} \\
\hline 4 & $\mathrm{Mg}_{65} \mathrm{Cu}_{25} \mathrm{Y}_{10}$ & 739 & 260 & 1.234 & 362 & -0.648 & 1.39 & 428 & 1.65 & 22.1 & {$[5,22]$} \\
\hline 5 & $\mathrm{Zr}_{65} \mathrm{Al}_{10} \mathrm{Ni}_{10} \mathrm{Cu}_{15}$ & 1161 & 437 & 1.353 & 660 & -0.624 & 1.51 & 641 & 1.47 & 16.5 & {$[22]$} \\
\hline 6 & $\mathrm{Zr}_{46.75} \mathrm{Ti}_{8.25} \mathrm{Cu}_{7.5} \mathrm{Ni}_{10} \mathrm{Be}_{27.5}$ & 1070 & 372 & 1.225 & 504 & -0.652 & 1.67 & 622 & 1.67 & 22.7 & {$[6,22]$} \\
& & & & & & & & & & & \\
\hline
\end{tabular}


